\section{Tendência temporal das internações por acidentes de trânsito na cidade de São Paulo, Brasil, 2000-2019}

\author{
Time trend in hospitalizations from motor \\ vehicle accidents in the city of São Paulo, \\ Brazil, 2000-2019
}

\section{Tendencia temporal de los internamientos por accidentes de tráfico en la ciudad de São Paulo, Brasil, 2000-2019}

Gleice Margarete de Souza Conceição 1

Gizelton Pereira Alencar 1

Maria do Rosário Dias de Oliveira Latorre 1

\title{
Resumo
}

Este estudo avaliou a tendência das taxas de internação por acidentes de trânsito no Sistema Único de Saúde (SUS), de residentes no Município de São Paulo, Brasil, entre 2000 e 2019, segundo sexo, faixa etária e meio de transporte (pedestres, ciclistas, motociclistas e ocupantes de veículo). Foi ajustado um modelo de regressão segmentada com resposta binomial negativa, com pontos de inflexão para acomodar possíveis mudanças de tendência. Foram registradas 189.765 internações durante o período de estudo, a maioria de homens (80,5\%) com idade entre 20 e 49 anos (71,2\%). O tipo de acidente mais frequente foi com motocicleta (42,8\%), seguido dos atropelamentos de pedestres $(33,7 \%)$. De um modo geral, o período de 2000 a 2007 foi marcado pelo crescimento das taxas de hospitalização por acidentes de trânsito para todos os meios de transporte, em ambos os sexos e na maioria das faixas etárias. O momento em que as taxas pararam de crescer ou que eventualmente passaram a cair foi diferente para os diferentes meios de transporte. Para ocupantes de veículos e ciclistas, a tendência na maioria das faixas etárias inverteu-se para uma de queda em 2008, mas para pedestres e motociclistas, isto só ocorreu em 2012. A partir de 2015, a queda cessou em pedestres e as taxas em ciclistas voltaram a subir, na maioria das faixas etárias. Para motociclistas, as taxas voltaram a crescer em homens de 20 a 59 anos (7,2\% ao ano, atingindo valores superiores a 140 por 100 mil habitantes em 2019) e em mulheres, de 15 a 39 anos (4,9\% ao ano). É possível que os benefícios das medidas de segurança implementadas até agora tenham atingido seu limite, de modo que as atuais medidas de controle e prevenção devem ser revistas.

Acidentes de Trânsito; Transportes; Hospitalização; Morbidade

\author{
Correspondência \\ G. M. S. Conceição \\ Faculdade de Saúde Pública, Universidade de São Paulo. \\ Av. Dr. Arnaldo 715, 1o andar, São Paulo, SP \\ 01246-904, Brasil. \\ gleice@usp.br \\ 1 Faculdade de Saúde Pública, Universidade de São Paulo, São \\ Paulo, Brasil.
}




\section{Introdução}

Os acidentes de trânsito constituem uma causa evitável de morte e, no entanto, matam mais de 1,35 milhão de pessoas todos os anos ao redor do mundo, principalmente nos países de renda média com crescentes índices de motorização. Embora ocupem a 8a posição no ranking de causas de óbito para todas as idades, com impacto semelhante ao de muitas doenças transmissíveis, como malária, por exemplo, são a primeira causa de óbito de pessoas entre 5 e 29 anos 1,2,3. Entretanto, nem todos os acidentes de trânsito têm o óbito como desfecho. Estima-se que para cada pessoa que morre no trânsito, vinte ficam feridas e, dentre estas, uma se tornará permanentemente incapacitada. Isto constitui um impacto emocional e social incomensurável, tanto para as vítimas quanto para as suas famílias, sem falar no impacto financeiro, que abrange custos diretos, como médicos e hospitais, e custos indiretos, como dias de ausência do trabalho, anos de produtividade e de vida perdidos ou vividos com incapacidades ${ }^{2}$. Além dos custos individuais, as lesões provocadas por acidentes de trânsito impõem um pesado ônus aos serviços de saúde e à economia das nações. Estima-se que o custo para os países, que provavelmente já enfrentam outros problemas de desenvolvimento, seja da ordem de $1 \%$ a $2 \%$ do seu produto nacional bruto 2 . Em 2019, os acidentes de trânsito foram responsáveis por mais de 79 milhões de anos de vida perdidos ajustados por incapacidade (DALY) no mundo. Para o Brasil, essa

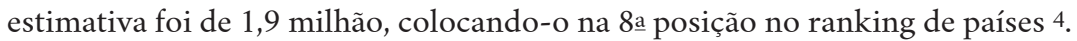

Considerado um dos países com o trânsito mais violento do mundo, nos últimos anos, o Brasil vem tentando conter o alto número de acidentes 5 . Os estudos de séries temporais envolvendo indicadores de morbidade resultante de acidentes de trânsito permitem caracterizar a frequência e a tendência desses eventos, constituindo ferramentas importantes para a detecção de mudanças acentuadas no risco e para o planejamento de medidas de prevenção e controle, além de apontar quais dessas práticas poderiam ter sido efetivas.

Alguns estudos avaliaram a magnitude e a tendência desses indicadores no Brasil e regiões, encontrando resultados diversos. Lentsck et al. 6, ao analisar taxas de internação por lesões traumáticas em unidades de terapia intensiva no Brasil de 1998 a 2015, observaram que as quedas e os acidentes de transporte foram as causas mais frequentes dos traumas, tendo havido aumento de 3,6\% ao ano, em média, nas taxas no Brasil, porém, maior na Região Norte $(8 \%)$, entre as mulheres $(5,4 \%)$ e pessoas com 60 anos ou mais (5,5\%). O estudo de Andrade \& Jorge 7 identificou 1.747.191 internações por acidentes de trânsito no Brasil entre 2000 e 2013, nas quais 23,5\% das vítimas apresentaram diagnóstico sugestivo de sequelas físicas. Houve estabilidade na tendência das taxas com diagnóstico sugestivo de sequelas físicas para o Brasil e regiões, mas tendência ascendente para sequelas visíveis nas regiões Centro-oeste e Norte, e para o sexo masculino. Marín-León et al. 8 , ao avaliarem acidentes de trânsito em Campinas, São Paulo, chamaram a atenção para os acidentes com motocicleta, responsáveis pela maior taxa de atropelamento e pela maior letalidade de pedestres, contabilizando 49,3\% dos acidentes fatais em vias públicas em 2008.

Tais estudos sugerem uma grande variabilidade no perfil de acidentes de uma área para outra. Isto ressalta a necessidade de estudos de caráter localizado, abrangendo pequenas áreas, a fim de identificar particularidades e susceptibilidades locais e contribuir na implementação de políticas específicas. Poucos estudos avaliaram a morbidade por acidentes de trânsito a níveis municipais, em subpopulações específicas, estabelecendo importantes lacunas a serem preenchidas.

São Paulo é a cidade mais populosa do Brasil, com mais de 12 milhões de habitantes e densidade populacional superior a $7 \mathrm{mil}$ habitantes $/ \mathrm{km}^{2}{ }^{9}$. Seu crescimento demográfico e desenvolvimento econômico não foram acompanhados por melhorias de infraestrutura equivalentes e, como efeito colateral, as questões relacionadas à mobilidade urbana passaram a interferir na qualidade de vida da população. A frota automotiva da cidade nas duas últimas décadas dobrou e, em particular, a frota de motocicletas quadruplicou 10 , de modo que a ocorrência de um número expressivo de acidentes de trânsito todos os dias não seria surpreendente.

Não existem estudos recentes sobre a tendência de indicadores de morbidade para a cidade de São Paulo. Este estudo tem por objetivo avaliar a tendência da taxa de internações por acidentes de trânsito no Município de São Paulo, no período de 2000 a 2019, e identificar as subpopulações mais suscetíveis com base no sexo, idade e meio de transporte das vítimas. 


\section{Material e métodos}

Trata-se de um estudo ecológico de séries temporais.

\section{Dados de internações}

Informações sobre o número de internações realizadas no Sistema Único de Saúde (SUS) na cidade de São Paulo no período de 2000 a 2019, cuja causa básica tenha sido "acidente de transporte terrestre", foram obtidas do Sistema de Informações Hospitalares do SUS (SIH/SUS), por meio do Departamento de Informática do SUS (DATASUS. http://www.datasus.gov.br). Esses dados foram obtidos apenas para residentes em São Paulo segundo ano, sexo, faixa etária e meio de transporte utilizado pela vítima.

Os acidentes de trânsito estão classificados segundo a 10ạ revisão da Classificação Internacional de Doenças (CID-10), sob os códigos de V01 a V89, subdivididos nas seguintes categorias, de acordo com o meio de transporte da vítima: pedestre (V01 a V09), bicicleta (V10 a V19), motocicleta (V20 a V29), triciclo (V30 a V39), automóvel (V40 a V49), caminhonete (V50 a V59), veículo de transporte pesado - VTP (V60 a V69), ônibus (V70 a V79) e indeterminado - outros acidentes de transporte terrestre (V80 a V89). Neste estudo, os acidentes de trânsito foram agrupados em quatro categorias: (1) pedestres (V01 a V09), (2) ciclistas (V10 a V19), (3) motociclistas (V20 a V29) e (4) ocupantes de demais veículos (automóvel, caminhonete, veículo de transporte pesado e ônibus) (V40 a V79).

As faixas etárias consideradas foram: de 0 a 14, 15 a 19, 20 a 39, 40 a 59 e 60 anos e mais.

\section{Dados sobre a população}

Informações sobre o tamanho da população residente em São Paulo, entre 2000 e 2019, segundo ano, sexo e faixa etária, também foram obtidas por meio do DATASUS.

\section{Análise estatística}

Foram calculadas taxas anuais de internação em cada um dos subgrupos determinados pelas combinações das categorias de meio de transporte, sexo e faixa etária. As taxas foram obtidas como a razão entre o número de internações e o tamanho da população residente em cada subgrupo, ano a ano, multiplicadas por 100 mil habitantes.

Para avaliar a tendência dessas taxas, bem como detectar mudanças nessa tendência ao longo do tempo, foi ajustado um modelo de regressão segmentada 11, com resposta binomial negativa, contendo pontos de inflexão nos anos de 2007, 2012 e 2015, como sugerido pela análise descritiva dos dados. A variável resposta foi o número anual de internações e as variáveis explicativas foram ano, meio de transporte, sexo, faixa etária, além de variáveis para acomodar os pontos de inflexão, convenientemente parametrizadas. $\mathrm{O}$ tamanho da população foi utilizado como controle (offset), permitindo a estimação posterior das taxas de internação.

Um intercepto e uma inclinação foram estimados para cada um dos quatro períodos determinados pelos pontos de inflexão (2000 a 2007, 2007 a 2012, 2012 a 2015 e 2015 a 2019), em cada um dos subgrupos. Para avaliar se a tendência era semelhante em diferentes períodos, bem como se a tendência em um determinado período era semelhante nas diferentes faixas etárias, foram construídos contrastes, sob a Hipótese Linear Geral 12, envolvendo as inclinações correspondentes. Nas situações em que essas inclinações não foram significativamente diferentes, uma única inclinação foi ajustada. Após este procedimento, obteve-se a variação percentual anual (APC) das taxas de hospitalização (ou seja, o aumento ou diminuição percentual na taxa de um ano em relação ao ano anterior), bem como a taxa ajustada no início e no final de cada período, para cada um dos subgrupos.

O nível de significância dos testes foi fixado em 0,05. Para avaliar se o modelo em questão estava bem ajustado, foi conduzida uma análise de resíduos. Essas análises foram realizadas com auxílio do software R for Windows (http://www.r-project.org). 


\section{Resultados}

Foram registradas 189.765 internações por acidentes de trânsito na cidade de São Paulo entre 2000 e 2019. Em 6,8\% dos casos, o meio de transporte da vítima não foi especificado. O sexo e a faixa etária foram especificados em todos os casos.

A Tabela 1 mostra a distribuição das internações segundo o meio de transporte da vítima, sexo e faixa etária. A grande maioria dos indivíduos era do sexo masculino (80,5\%), com idade entre 20 e 49 anos $(71,2 \%)$. O tipo de acidente mais frequente foi com motocicleta $(42,8 \%)$, seguido dos atropelamentos de pedestres $(33,7 \%)$. Ocupantes de veículo motorizado, com exceção da motocicleta, totalizaram $10,8 \%$ das internações.

A Tabela 2 mostra a distribuição das internações segundo o meio de transporte da vítima (agora agrupados nas quatro categorias de interesse do estudo), para cada faixa etária e sexo. Crianças até 14 anos e indivíduos com 40 anos e mais, de ambos os sexos, estiveram mais suscetíveis a serem internados por atropelamento. Entre 15 e 39 anos, os homens foram mais frequentemente internados por acidentes com motocicleta, e as mulheres, por acidentes com motocicleta e atropelamentos. Os acidentes com ciclistas foram os menos frequentes em ambos os sexos, principalmente nas faixas etárias acima de 14 anos.

\section{Tabela 1}

Distribuição das internações segundo meio de transporte da vítima, sexo e faixa etária. Município de São Paulo, Brasil, 2000-2019.

\begin{tabular}{lcc}
\hline & $\mathbf{n}$ & $\%$ \\
\hline Total & 189.765 & 100,0 \\
Meio de transporte & & \\
Pedestre & 63.864 & 33,7 \\
Bicicleta & 10.776 & 5,7 \\
Motocicleta & 81.264 & 42,8 \\
Triciclo & 504 & 0,3 \\
Automóvel & 18.195 & 9,6 \\
Caminhonete & 332 & 0,2 \\
Transporte pesado & 785 & 0,4 \\
Ônibus & 1.149 & 0,6 \\
Outros & 12.896 & 6,8 \\
Sexo & & 80,5 \\
Masculino & 152.789 & 19,5 \\
Feminino & 36.976 & \\
Faixa etária (anos) & & 9,2 \\
0-14 & 17.468 & 12,4 \\
15-19 & 23.568 & 52,2 \\
20-39 & 99.080 & 19,0 \\
$40-59$ & 36.036 & 7,2 \\
60 e mais & 13.613 & \\
\hline
\end{tabular}


Tabela 2

Distribuição das internações segundo o meio de transporte da vítima, por faixa etária e sexo. Município de São Paulo, Brasil, 2000-2019.

\begin{tabular}{|c|c|c|c|c|c|c|c|c|c|c|}
\hline \multirow{2}{*}{$\begin{array}{l}\text { Faixa etária } \\
\text { (anos) }\end{array}$} & \multicolumn{2}{|c|}{ Pedestre } & \multicolumn{2}{|c|}{ Ciclista } & \multicolumn{2}{|c|}{ Motociclista } & \multicolumn{2}{|c|}{ Ocupante } & \multicolumn{2}{|c|}{ Total } \\
\hline & $\mathbf{n}$ & $\%$ & $\mathbf{n}$ & $\%$ & $\mathbf{n}$ & $\%$ & $\mathbf{n}$ & $\%$ & $\mathbf{n}$ & $\%$ \\
\hline \multicolumn{11}{|l|}{ Masculino } \\
\hline $0-14$ & 6.294 & 61,0 & 2.252 & 21,8 & 1.069 & 10,4 & 700 & 6,8 & 10.315 & 100,0 \\
\hline $15-19$ & 3.281 & 19,5 & 1.401 & 8,3 & 10.875 & 64,6 & 1.278 & 7,6 & 16.835 & 100,0 \\
\hline 20-39 & 14.822 & 19,6 & 3.517 & 4,6 & 49.602 & 65,5 & 7.791 & 10,3 & 75.732 & 100,0 \\
\hline $40-59$ & 11.213 & 45,5 & 1.499 & 6,1 & 8.804 & 35,7 & 3.129 & 12,7 & 24.645 & 100,0 \\
\hline 60 e mais & 4.898 & 72,3 & 257 & 3,8 & 768 & 11,3 & 848 & 12,5 & 6.771 & 100,0 \\
\hline Total & 40.508 & 30,2 & 8.926 & 6,6 & 71.118 & 53,0 & 13.746 & 10,2 & 134.298 & 100,0 \\
\hline \multicolumn{11}{|l|}{ Feminino } \\
\hline $0-14$ & 2.930 & 65,0 & 647 & 14,4 & 415 & 9,2 & 513 & 11,4 & 4.505 & 100,0 \\
\hline $15-19$ & 1.448 & 37,5 & 176 & 4,6 & 1.648 & 42,7 & 590 & 15,3 & 3.862 & 100,0 \\
\hline $20-39$ & 4.468 & 39,4 & 318 & 2,8 & 4.423 & 39,0 & 2.118 & 18,7 & 11.327 & 100,0 \\
\hline $40-59$ & 4.300 & 64,7 & 194 & 2,9 & 1.015 & 15,3 & 1.139 & 17,1 & 6.648 & 100,0 \\
\hline 60 e mais & 4.007 & 80,1 & 76 & 1,5 & 370 & 7,4 & 551 & 11,0 & 5.004 & 100,0 \\
\hline Total & 17.153 & 54,7 & 1.411 & 4,5 & 7.871 & 25,1 & 4.911 & 15,7 & 31.346 & 100,0 \\
\hline
\end{tabular}

A Figura 1 mostra as taxas de internações observadas (representadas por pontos) e ajustadas (representadas por linhas) ao longo do tempo segundo sexo, meio de transporte da vítima e faixa etária. A Tabela 3 apresenta as estimativas do modelo de regressão ajustado: a APC estimada em cada um dos quatro períodos e seu intervalo de confiança (IC), além das taxas de internações (por 100 mil habitantes) ajustadas no início e no final de cada período, segundo sexo, meio de transporte da vítima e faixa etária.

Entre 2000 e 2007, as taxas cresceram acentuadamente para todos os meios de transporte, em ambos os sexos e na maioria das faixas etárias. Para ocupantes de veículos e ciclistas, a tendência na maioria das faixas etárias inverteu-se para uma de queda em 2008 e, para pedestres e motociclistas, em 2012. A partir de 2015, as taxas continuaram em queda para ocupantes, estabilizaram-se para pedestres e voltaram a aumentar para ciclistas e motociclistas em faixas etárias específicas. Os resultados mais detalhados estão apresentados a seguir.

No sexo masculino, entre 2000 e 2007 , a taxa de atropelamentos permaneceu estável entre indivíduos de 15 a 39 anos, mas cresceu nas demais faixas etárias, mais acentuadamente nas de 0 a 14 anos e de 60 anos e mais (5,6\% ao ano, IC: 4,0; 7,2). Em 2007, a tendência inverteu-se na faixa de 0 a 14 anos e a taxa passou a diminuir 7,8\% ao ano (IC: 6,$8 ; 8,8)$ até o final do período de estudo e, na faixa de 60 anos e mais, o crescimento cessou. Nas faixas de 20 a 59 anos o quadro permaneceu inalterado, mas na faixa de 15 a 19 anos, a taxa que antes era estável começou a aumentar (6,7\% ao ano, IC: 4,4; 9,2). A partir de 2012 , a tendência foi de queda em todas as faixas etárias: $7,8 \%$ ao ano (IC: 6,$8 ; 8,8)$ nas menores de 20 anos e 15,6\% ao ano (IC: 13,0; 18,0) nas de 20 anos e mais. Entretanto, nestas últimas, o decréscimo cessou em 2015.

Em ciclistas do sexo masculino, as taxas apresentaram crescimento intenso em todas as faixas etárias entre 2000 e 2007 (17\% ao ano, IC: 15,0; 19,0). Em 2007, a tendência se inverteu e as taxas caíram, mais acentuadamente na faixa de 20 a 39 anos (14,7\% ao ano, IC: 11,7; 17,5); nas demais, o decréscimo foi de $3,9 \%$ ao ano (IC: 2,4; 5,2). Entre 2012 e 2015, a queda tornou-se mais acentuada nas faixas de 0 a 19 anos (15,3\% ao ano, IC: 11,6; 18,9), mas cessou na de 20 a 39 anos. Em 2015, a queda também cessou na faixa de $0-14$ anos e, nas faixas de 15 a 59 anos, as taxas voltaram a crescer $(9,1 \%$ ao ano, IC: $5,4 ; 13,0)$. Durante todo o período, a faixa de 15 a 19 anos apresentou taxas superiores às demais. Em 2019, as taxas em todas as faixas etárias encontravam-se em patamares superiores àqueles observados no início do estudo. 
Figura 1

Taxas de internações observadas (pontos) e ajustadas pelo modelo de regressão (linhas), segundo sexo, meio de transporte da vítima e faixa etária. Município de São Paulo, Brasil, 2000-2019.

1a) Pedestre (masculino)

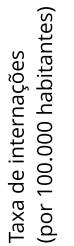

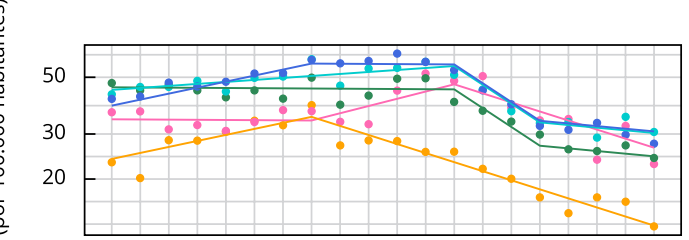

2000200220042006200820102012201420162018

Ano 1b) Pedestre (feminino)
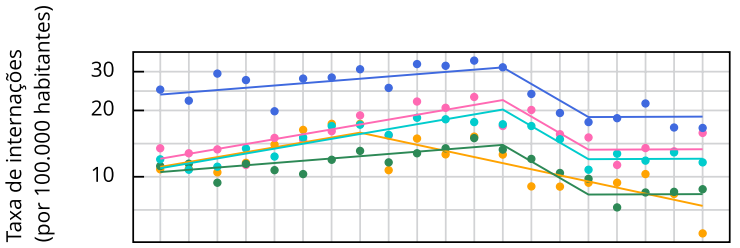

2000200220042006200820102012201420162018

Ano

1d) Ciclista (feminino)

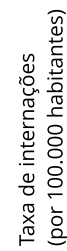

Ano

1e) Motociclista (masculino)

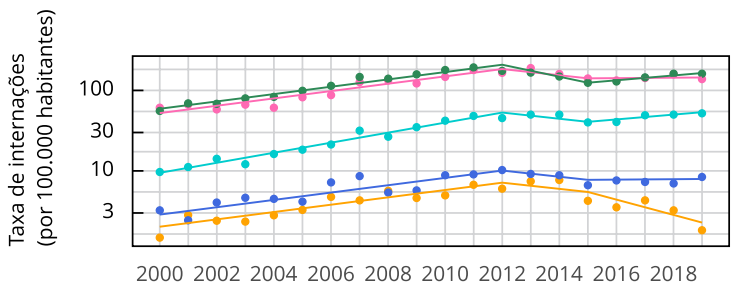

Ano

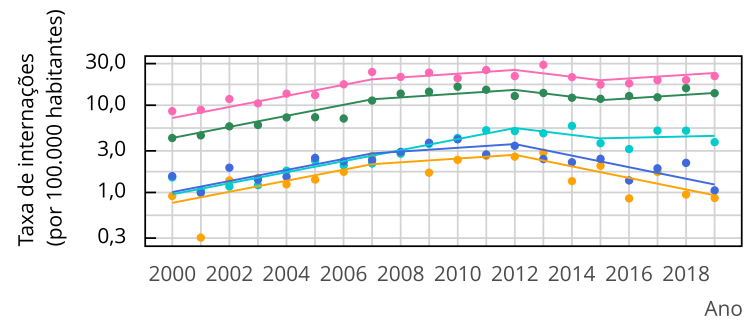

1g) Ocupante (masculino)

1h) Ocupante (feminino)

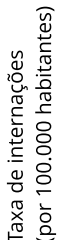

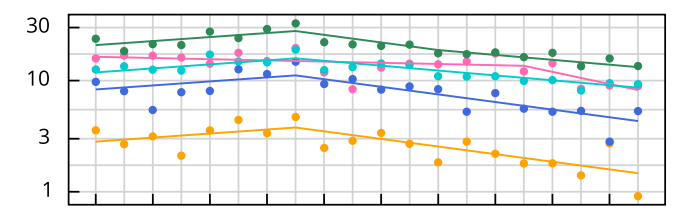

2000200220042006200820102012201420162018

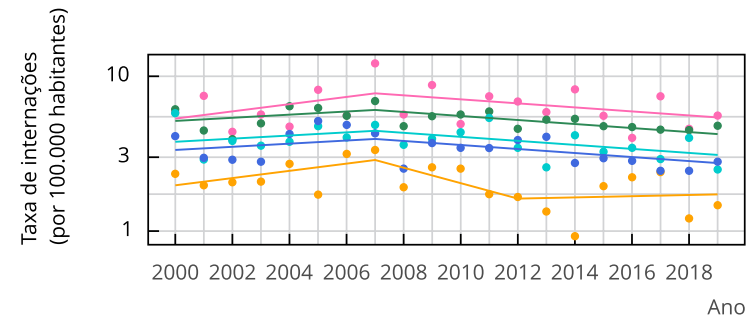


Tabela 3

Variação percentual anual (APC) e tendência (T) estimadas em cada período e taxa de internações ajustada no início e no final de cada período, segundo sexo, meio de transporte da vítima e faixa etária. Município de São Paulo, Brasil, 2000-2019.

\begin{tabular}{|c|c|c|c|c|c|c|c|c|c|c|c|c|c|}
\hline & $\begin{array}{l}\text { Taxa } \\
2000\end{array}$ & $\begin{array}{c}\text { APC (IC) } \\
2000-2007\end{array}$ & $\mathbf{T}$ & $\begin{array}{l}\text { Taxa } \\
2007\end{array}$ & $\begin{array}{c}\text { APC (IC) } \\
2007-2012\end{array}$ & $T$ & $\begin{array}{l}\text { Taxa } \\
2012\end{array}$ & $\begin{array}{c}\text { APC (IC) } \\
2012-2015\end{array}$ & $\mathbf{T}$ & $\begin{array}{l}\text { Taxa } \\
2015\end{array}$ & $\begin{array}{c}\text { APC (IC) } \\
2015-2019\end{array}$ & $\mathbf{T}$ & $\begin{array}{l}\text { Taxa } \\
2019\end{array}$ \\
\hline \multicolumn{14}{|l|}{ Masculino } \\
\hline \multicolumn{14}{|l|}{ Pedestres } \\
\hline 0-14 & 24,0 & $\begin{array}{c}5,6 \text { * } \\
(4,0 ; 7,2)\end{array}$ & $\uparrow$ & 35,0 & $\begin{array}{c}-7,8 \text { * } \\
(-8,8 ;-6,8)\end{array}$ & $\downarrow$ & 23,3 & $\begin{array}{c}-7,8 \text { * } \\
(-8,8 ;-6,8)\end{array}$ & $\downarrow$ & 18,2 & $\begin{array}{c}-7,8 * \\
(-8,8 ;-6,8)\end{array}$ & $\downarrow$ & 13,2 \\
\hline $15-19$ & 34,2 & $\begin{array}{c}-0,2 \\
(-1,1 ; 0,8)\end{array}$ & - & 33,9 & $\begin{array}{c}6,7 * \\
(4,4 ; 9,2)\end{array}$ & $\uparrow$ & 46,9 & $\begin{array}{c}-7,8 \text { * } \\
(-8,8 ;-6,8)\end{array}$ & $\downarrow$ & 36,7 & $\begin{array}{c}-7,8 \text { * } \\
(-8,8 ;-6,8)\end{array}$ & $\downarrow$ & 26,5 \\
\hline $20-39$ & 45,7 & $\begin{array}{c}-0,2 \\
(-1,1 ; 0,8)\end{array}$ & - & 45,2 & $\begin{array}{c}-0,2 \\
(-1,1 ; 0,8)\end{array}$ & - & 44,8 & $\begin{array}{c}-15,6 \text { * } \\
(-18,0 ;-13,0)\end{array}$ & $\downarrow$ & 27,0 & $\begin{array}{c}-2,4 \\
(-5,2 ; 0,6)\end{array}$ & - & 24,5 \\
\hline $40-59$ & 44,6 & $\begin{array}{c}1,8 \text { * } \\
(0,8 ; 2,8)\end{array}$ & $\uparrow$ & 50,6 & $\begin{array}{c}1,8 \text { * } \\
(0,8 ; 2,8)\end{array}$ & $\uparrow$ & 55,3 & $\begin{array}{c}-15,6 \text { * } \\
(-18,0 ;-13,0)\end{array}$ & $\downarrow$ & 33,3 & $\begin{array}{c}-2,4 \\
(-5,2 ; 0,6)\end{array}$ & - & 30,3 \\
\hline 60 e mais & 38,7 & $\begin{array}{c}5,6 \text { * } \\
(4,0 ; 7,2)\end{array}$ & $\uparrow$ & 56,6 & $\begin{array}{c}-0,2 \\
(-1,1 ; 0,8)\end{array}$ & - & 56,1 & $\begin{array}{c}-15,6 \text { * } \\
(-18,0 ;-13,0)\end{array}$ & $\downarrow$ & 33,8 & $\begin{array}{c}-2,4 \\
(-5,2 ; 0,6)\end{array}$ & - & 30,7 \\
\hline \multicolumn{14}{|l|}{ Ciclistas } \\
\hline $0-14$ & 4,4 & $\begin{array}{c}17,0 \text { * } \\
(15,0 ; 19,0)\end{array}$ & $\uparrow$ & 13,4 & $\begin{array}{c}-3,9 * \\
(-5,4 ;-2,4)\end{array}$ & $\downarrow$ & 10,9 & $\begin{array}{c}-15,3 \text { * } \\
(-18,9 ;-11,6)\end{array}$ & $\downarrow$ & 6,7 & $\begin{array}{c}3,1 \\
(-3,0 ; 9,6)\end{array}$ & - & 7,5 \\
\hline $15-19$ & 7,6 & $\begin{array}{c}17,0 \text { * } \\
(15,0 ; 19,0)\end{array}$ & $\uparrow$ & 22,8 & $\begin{array}{c}-3,9 * \\
(-5,4 ;-2,4)\end{array}$ & $\downarrow$ & 18,7 & $\begin{array}{c}-15,3 * \\
(-18,9 ;-11,6)\end{array}$ & $\downarrow$ & 11,4 & $\begin{array}{c}9,1 \text { * } \\
(5,4 ; 13,0)\end{array}$ & $\uparrow$ & 16,1 \\
\hline $20-39$ & 5,1 & $\begin{array}{c}17,0 \text { * } \\
(15,0 ; 19,0)\end{array}$ & $\uparrow$ & 15,3 & $\begin{array}{c}-14,7 * \\
(-17,5 ;-11,7)\end{array}$ & $\downarrow$ & 6,9 & $\begin{array}{c}3,7 \\
(-2,4 ; 10,2)\end{array}$ & - & 7,7 & $\begin{array}{c}9,1 \text { * } \\
(5,4 ; 13,0)\end{array}$ & $\uparrow$ & 10,9 \\
\hline $40-59$ & 2,5 & $\begin{array}{c}17,0 \text { * } \\
(15,0 ; 19,0)\end{array}$ & $\uparrow$ & 7,6 & $\begin{array}{c}-3,9 * \\
(-5,4 ;-2,4)\end{array}$ & $\downarrow$ & 6,2 & $\begin{array}{c}-3,9 * \\
(-5,4 ;-2,4)\end{array}$ & $\downarrow$ & 5,5 & $\begin{array}{c}9,1 \text { * } \\
(5,4 ; 13,0)\end{array}$ & $\uparrow$ & 7,8 \\
\hline 60 e mais & 1,1 & $\begin{array}{c}17,0 \text { * } \\
(15,0 ; 19,0)\end{array}$ & $\uparrow$ & 3,2 & $\begin{array}{c}-3,9 * \\
(-5,4 ;-2,4)\end{array}$ & $\downarrow$ & 2,6 & $\begin{array}{c}-3,9 * \\
(-5,4 ;-2,4)\end{array}$ & $\downarrow$ & 2,3 & $\begin{array}{c}-3,9 * \\
(-5,4 ;-2,4)\end{array}$ & $\uparrow$ & 2,0 \\
\hline \multicolumn{14}{|l|}{ Motociclistas } \\
\hline $0-14$ & 2,0 & $\begin{array}{c}11,1 \text { * } \\
(10,3 ; 11,9)\end{array}$ & $\uparrow$ & 4,2 & $\begin{array}{c}11,1 \text { * } \\
(10,3 ; 11,9)\end{array}$ & $\uparrow$ & 7,1 & $\begin{array}{c}-8,5 * \\
(-11,0 ;-5,9)\end{array}$ & $\downarrow$ & 5,5 & $\begin{array}{c}-19,7 \text { * } \\
(-25,7 ;-13,4)\end{array}$ & $\downarrow$ & 2,3 \\
\hline $15-19$ & 52,3 & $\begin{array}{c}11,1 \text { * } \\
(10,3 ; 11,9)\end{array}$ & $\uparrow$ & 109,0 & $\begin{array}{c}11,1 \text { * } \\
(10,3 ; 11,9)\end{array}$ & $\uparrow$ & 184,4 & $\begin{array}{c}-8,5 * \\
(-11,0 ;-5,9)\end{array}$ & $\downarrow$ & 141,4 & $\begin{array}{c}0,6 \\
(-2,9 ; 4,3)\end{array}$ & - & 144,8 \\
\hline 20-39 & 59,2 & $\begin{array}{c}11,1 \text { * } \\
(10,3 ; 11,9)\end{array}$ & $\uparrow$ & 123,4 & $\begin{array}{c}11,1 \text { * } \\
(10,3 ; 11,9)\end{array}$ & $\uparrow$ & 208,7 & $\begin{array}{c}-15,8 * \\
(-18,7 ;-12,7)\end{array}$ & $\downarrow$ & 124,7 & $\begin{array}{c}7,2 \text { * } \\
(4,0 ; 10,4)\end{array}$ & $\uparrow$ & 164,4 \\
\hline $40-59$ & 9,5 & $\begin{array}{c}15,5 \text { * } \\
(14,0 ; 16,9)\end{array}$ & $\uparrow$ & 25,9 & $\begin{array}{c}15,5 \text { * } \\
(14,0 ; 16,9)\end{array}$ & $\uparrow$ & 53,1 & $\begin{array}{c}-8,5 * \\
(-11,0 ;-5,9)\end{array}$ & $\downarrow$ & 40,7 & $\begin{array}{c}7,2 \text { * } \\
(4,0 ; 10,4)\end{array}$ & $\uparrow$ & 53,7 \\
\hline 60 e mais & 2,9 & $\begin{array}{c}11,1 \text { * } \\
(10,3 ; 11,9)\end{array}$ & $\uparrow$ & 6,0 & $\begin{array}{c}11,1 \text { * } \\
(10,3 ; 11,9)\end{array}$ & $\uparrow$ & 10,1 & $\begin{array}{c}-8,5 * \\
(-11,0 ;-5,9)\end{array}$ & $\downarrow$ & 7,7 & $\begin{array}{c}0,6 \\
(-2,9 ; 4,3)\end{array}$ & - & 7,9 \\
\hline \multicolumn{14}{|l|}{ Ocupantes } \\
\hline 0-14 & 2,8 & $\begin{array}{c}4,3 \text { * } \\
(2,7 ; 5,8)\end{array}$ & $\uparrow$ & 3,8 & $\begin{array}{c}-7,6 * \\
(-8,7 ;-6,4)\end{array}$ & $\downarrow$ & 2,6 & $\begin{array}{c}-7,6 * \\
(-8,7 ;-6,4)\end{array}$ & $\downarrow$ & 2,0 & $\begin{array}{c}-7,6 * \\
(-8,7 ;-6,4)\end{array}$ & $\downarrow$ & 1,5 \\
\hline $15-19$ & 16,4 & $\begin{array}{c}-1,2 \\
(-2,6 ; 0,2)\end{array}$ & - & 15,0 & $\begin{array}{c}-1,2 \\
(-2,6 ; 0,2)\end{array}$ & - & 14,1 & $\begin{array}{c}-1,2 \\
(-2,6 ; 0,2)\end{array}$ & - & 13,6 & $\begin{array}{c}-11,8 \text { ** } \\
(-18,4 ;-4,9)\end{array}$ & $\downarrow$ & 8,2 \\
\hline $20-39$ & 20,9 & $\begin{array}{c}4,3 \text { * } \\
(2,7 ; 5,8)\end{array}$ & $\uparrow$ & 27,9 & $\begin{array}{c}-7,6 * \\
(-8,7 ;-6,4)\end{array}$ & $\downarrow$ & 18,8 & $\begin{array}{c}-4,9 * \\
(-5,9 ;-3,9)\end{array}$ & $\downarrow$ & 16,2 & $\begin{array}{c}-4,9 * \\
(-5,9 ;-3,9)\end{array}$ & $\downarrow$ & 13,2 \\
\hline $40-59$ & 11,8 & $\begin{array}{c}4,3 * \\
(2,7 ; 5,8)\end{array}$ & $\uparrow$ & 15,8 & $\begin{array}{c}-4,9 * \\
(-5,9 ;-3,9)\end{array}$ & $\downarrow$ & 12,3 & $\begin{array}{c}-4,9 * \\
(-5,9 ;-3,9)\end{array}$ & $\downarrow$ & 10,6 & $\begin{array}{c}-4,9 \text { * } \\
(-5,9 ;-3,9)\end{array}$ & $\downarrow$ & 8,6 \\
\hline 60 e mais & 8,3 & $\begin{array}{c}4,3 * \\
(2,7 ; 5,8)\end{array}$ & $\uparrow$ & 11,1 & $\begin{array}{c}-7,6 \text { * } \\
(-8,7 ;-6,4)\end{array}$ & $\downarrow$ & 7,5 & $\begin{array}{c}-7,6 \text { * } \\
(-8,7 ;-6,4)\end{array}$ & $\downarrow$ & 5,9 & $\begin{array}{c}-7,6 \text { * } \\
(-8,7 ;-6,4)\end{array}$ & $\downarrow$ & 4,3 \\
\hline
\end{tabular}

(continua) 


\begin{tabular}{|c|c|c|c|c|c|c|c|c|c|c|c|c|c|}
\hline & $\begin{array}{l}\text { Taxa } \\
2000\end{array}$ & $\begin{array}{c}\text { APC (IC) } \\
2000-2007\end{array}$ & $\mathbf{T}$ & $\begin{array}{l}\text { Taxa } \\
2007\end{array}$ & $\begin{array}{c}\text { APC (IC) } \\
2007-2012\end{array}$ & $\mathbf{T}$ & $\begin{array}{l}\text { Taxa } \\
2012\end{array}$ & $\begin{array}{c}\text { APC (IC) } \\
2012-2015\end{array}$ & $\mathbf{T}$ & $\begin{array}{l}\text { Taxa } \\
2015\end{array}$ & $\begin{array}{c}\text { APC (IC) } \\
2015-2019\end{array}$ & $\mathbf{T}$ & $\begin{array}{l}\text { Taxa } \\
2019\end{array}$ \\
\hline \multicolumn{14}{|l|}{ Feminino } \\
\hline \multicolumn{14}{|l|}{ Pedestres } \\
\hline 0-14 & 11,1 & $\begin{array}{c}5,2 \text { * } \\
(4,3 ; 6,2)\end{array}$ & $\uparrow$ & 15,9 & $\begin{array}{c}-6,2 \text { * } \\
(-7,4 ;-5,0)\end{array}$ & $\downarrow$ & 11,5 & $\begin{array}{c}-6,2 \text { * } \\
(-7,4 ;-5,0)\end{array}$ & $\downarrow$ & 9,5 & $\begin{array}{c}-6,2 \text { * } \\
(-7,4 ;-5,0)\end{array}$ & $\downarrow$ & 7,4 \\
\hline $15-19$ & 12,1 & $\begin{array}{c}5,2 \text { * } \\
(4,3 ; 6,2)\end{array}$ & $\uparrow$ & 17,3 & $\begin{array}{c}5,2 \text { * } \\
(4,3 ; 6,2)\end{array}$ & $\uparrow$ & 22,3 & $\begin{array}{c}-15,9 * \\
(-18,5 ;-13,2)\end{array}$ & $\downarrow$ & 13,3 & $\begin{array}{c}0,1 \\
(-3,0 ; 3,3)\end{array}$ & - & 13,3 \\
\hline $20-39$ & 10,5 & $\begin{array}{c}2,4 \text { * } \\
(1,5 ; 3,3)\end{array}$ & $\uparrow$ & 12,4 & $\begin{array}{c}2,4 \text { * } \\
(1,5 ; 3,3)\end{array}$ & $\uparrow$ & 14,0 & $\begin{array}{c}-15,9 * \\
(-18,5 ;-13,2)\end{array}$ & $\downarrow$ & 8,3 & $\begin{array}{c}0,1 \\
(-3,0 ; 3,3)\end{array}$ & - & 8,3 \\
\hline $40-59$ & 10,9 & $\begin{array}{c}5,2 \text { * } \\
(4,3 ; 6,2)\end{array}$ & $\uparrow$ & 15,6 & $\begin{array}{c}5,2 \text { * } \\
(4,3 ; 6,2)\end{array}$ & $\uparrow$ & 20,2 & $\begin{array}{c}-15,9 * \\
(-18,5 ;-13,2)\end{array}$ & $\downarrow$ & 12,0 & $\begin{array}{c}0,1 \\
(-3,0 ; 3,3)\end{array}$ & - & 12,1 \\
\hline 60 e mais & 23,6 & $\begin{array}{c}2,4 \text { * } \\
(1,5 ; 3,3)\end{array}$ & $\uparrow$ & 27,9 & $\begin{array}{c}2,4 \text { * } \\
(1,5 ; 3,3)\end{array}$ & $\uparrow$ & 31,4 & $\begin{array}{c}-15,9 * \\
(-18,5 ;-13,2)\end{array}$ & $\downarrow$ & 18,7 & $\begin{array}{c}0,1 \\
(-3,0 ; 3,3)\end{array}$ & - & 18,8 \\
\hline \multicolumn{14}{|l|}{ Ciclistas } \\
\hline $0-14$ & 1,7 & $\begin{array}{c}14,5 \text { * } \\
(10,7 ; 18,4)\end{array}$ & $\uparrow$ & 4,3 & $\begin{array}{c}-8,6 \text { * } \\
(-10,6 ;-6,5)\end{array}$ & $\downarrow$ & 2,7 & $\begin{array}{c}-8,6 \text { * } \\
(-10,6 ;-6,5)\end{array}$ & $\downarrow$ & 2,1 & $\begin{array}{c}-8,6 \text { * } \\
(-10,6 ;-6,5)\end{array}$ & $\downarrow$ & 1,5 \\
\hline $15-19$ & 1,3 & $\begin{array}{c}14,5 \text { * } \\
(10,7 ; 18,4)\end{array}$ & $\uparrow$ & 3,3 & $\begin{array}{c}-16,7 \text { * } \\
(-23,1 ;-9,8)\end{array}$ & $\downarrow$ & 1,3 & $\begin{array}{c}5,9 * * * \\
(0,3 ; 11,7)\end{array}$ & $\uparrow$ & 1,6 & $\begin{array}{c}5,9 * \star \star \\
(0,3 ; 11,7)\end{array}$ & $\uparrow$ & 2,0 \\
\hline $20-39$ & 0,4 & $\begin{array}{c}14,5 \text { * } \\
(10,7 ; 18,4)\end{array}$ & $\uparrow$ & 1,1 & $\begin{array}{c}-8,6 \text { * } \\
(-10,6 ;-6,5)\end{array}$ & $\downarrow$ & 0,7 & $\begin{array}{c}-8,6 \text { * } \\
(-10,6 ;-6,5)\end{array}$ & $\downarrow$ & 0,5 & $\begin{array}{c}25,3 * \\
(13,7 ; 37,6)\end{array}$ & $\uparrow$ & 1,3 \\
\hline $40-59$ & 0,3 & $\begin{array}{c}14,5 \text { * } \\
(10,7 ; 18,4)\end{array}$ & $\uparrow$ & 0,8 & $\begin{array}{c}-4,3 \\
(-8,7 ; 0,3)\end{array}$ & - & 0,6 & $\begin{array}{c}5,9 * * * \\
(0,3 ; 11,7)\end{array}$ & $\uparrow$ & 0,7 & $\begin{array}{c}5,9 * * * \\
(0,3 ; 11,7)\end{array}$ & $\uparrow$ & 0,9 \\
\hline 60 e mais & 0,2 & $\begin{array}{c}14,5 \text { * } \\
(10,7 ; 18,4)\end{array}$ & $\uparrow$ & 0,6 & $\begin{array}{c}-4,3 \\
(-8,7 ; 0,3)\end{array}$ & - & 0,5 & $\begin{array}{c}-4,3 \\
(-8,7 ; 0,3)\end{array}$ & - & 0,5 & $\begin{array}{c}-4,3 \\
(-8,7 ; 0,3)\end{array}$ & - & 0,4 \\
\hline \multicolumn{14}{|l|}{ Motociclistas } \\
\hline 0-14 & 0,8 & $\begin{array}{c}15,7 \text { * } \\
(13,8 ; 17,6)\end{array}$ & $\uparrow$ & 2,1 & $\begin{array}{c}5,1 * \\
(2,9 ; 7,3)\end{array}$ & $\uparrow$ & 2,7 & $\begin{array}{c}-14,2 \text { * } \\
(-17,5 ;-10,8)\end{array}$ & $\downarrow$ & 1,7 & $\begin{array}{c}-14,2 \text { * } \\
(-17,5 ;-10,8)\end{array}$ & $\downarrow$ & 0,9 \\
\hline $15-19$ & 7,1 & $\begin{array}{c}15,7 \text { * } \\
(13,8 ; 17,6)\end{array}$ & $\uparrow$ & 19,8 & $\begin{array}{c}5,1 \text { * } \\
(2,9 ; 7,3)\end{array}$ & $\uparrow$ & 25,4 & $\begin{array}{c}-8,7 \text { * } \\
(-12,2 ;-4,9)\end{array}$ & $\downarrow$ & 19,4 & $\begin{array}{c}4,9 * * * \\
(0,7 ; 9,3)\end{array}$ & $\uparrow$ & 23,4 \\
\hline $20-39$ & 4,2 & $\begin{array}{c}15,7 \text { * } \\
(13,8 ; 17,6)\end{array}$ & $\uparrow$ & 11,7 & $\begin{array}{c}5,1 * \\
(2,9 ; 7,3)\end{array}$ & $\uparrow$ & 15,0 & $\begin{array}{c}-8,7 \text { * } \\
(-12,2 ;-4,9)\end{array}$ & $\downarrow$ & 11,4 & $\begin{array}{c}4,9 * \star \star \\
(0,7 ; 9,3)\end{array}$ & $\uparrow$ & 13,8 \\
\hline $40-59$ & 1,0 & $\begin{array}{c}15,7 \text { * } \\
(13,8 ; 17,6)\end{array}$ & $\uparrow$ & 2,6 & $\begin{array}{c}15,7 \text { * } \\
(13,8 ; 17,6)\end{array}$ & $\uparrow$ & 5,5 & $\begin{array}{c}-8,7 \text { * } \\
(-12,2 ;-4,9)\end{array}$ & $\downarrow$ & 4,2 & $\begin{array}{c}1,7 \\
(-4,7 ; 8,4)\end{array}$ & - & 4,5 \\
\hline 60 e mais & 1,0 & $\begin{array}{c}15,7 \text { * } \\
(13,8 ; 17,6)\end{array}$ & $\uparrow$ & 2,8 & $\begin{array}{c}5,1 * \\
(2,9 ; 7,3)\end{array}$ & $\uparrow$ & 3,6 & $\begin{array}{c}-14,2 \text { * } \\
(-17,5 ;-10,8)\end{array}$ & $\downarrow$ & 2,3 & $\begin{array}{c}-14,2 \text { * } \\
(-17,5 ;-10,8)\end{array}$ & $\downarrow$ & 1,2 \\
\hline \multicolumn{14}{|l|}{ Ocupantes } \\
\hline 0-14 & 2,0 & $\begin{array}{c}5,5 * * \\
(2,2 ; 9,0)\end{array}$ & $\uparrow$ & 2,9 & $\begin{array}{c}-10,8 \text { * } \\
(-16,3 ;-5,2)\end{array}$ & $\downarrow$ & 1,6 & $\begin{array}{c}0,9 \\
(-5,2 ; 7,3)\end{array}$ & - & 1,7 & $\begin{array}{c}0,9 \\
(-5,2 ; 7,3)\end{array}$ & - & 1,7 \\
\hline $15-19$ & 5,3 & $\begin{array}{c}5,5 * \star \\
(2,2 ; 9,0)\end{array}$ & $\uparrow$ & 7,8 & $\begin{array}{c}-2,9 * \\
(-3,9 ;-2,0)\end{array}$ & $\downarrow$ & 6,7 & $\begin{array}{c}-2,9 \text { * } \\
(-3,9 ;-2,0)\end{array}$ & $\downarrow$ & 6,1 & $\begin{array}{c}-2,9 * \\
(-3,9 ;-2,0)\end{array}$ & $\downarrow$ & 5,4 \\
\hline $20-39$ & 5,1 & $\begin{array}{c}2,4 * \star \star \\
(0,3 ; 4,5)\end{array}$ & $\uparrow$ & 6,1 & $\begin{array}{c}-2,9 * \\
(-3,9 ;-2,0)\end{array}$ & $\downarrow$ & 5,2 & $\begin{array}{c}-2,9 * \\
(-3,9 ;-2,0)\end{array}$ & $\downarrow$ & 4,8 & $\begin{array}{c}-2,9 * \\
(-3,9 ;-2,0)\end{array}$ & $\downarrow$ & 4,2 \\
\hline $40-59$ & 3,8 & $\begin{array}{c}2,4 * \star * \\
(0,3 ; 4,5)\end{array}$ & $\uparrow$ & 4,4 & $\begin{array}{c}-2,9 * \\
(-3,9 ;-2,0)\end{array}$ & $\downarrow$ & 3,8 & $\begin{array}{c}-2,9 * \\
(-3,9 ;-2,0)\end{array}$ & $\downarrow$ & 3,5 & $\begin{array}{c}-2,9 * \\
(-3,9 ;-2,0)\end{array}$ & $\downarrow$ & 3,1 \\
\hline 60 e mais & 3,3 & $\begin{array}{c}2,4 * \star * \\
(0,3 ; 4,5)\end{array}$ & $\uparrow$ & 3,9 & $\begin{array}{c}-2,9 * \\
(-3,9 ;-2,0)\end{array}$ & $\downarrow$ & 3,4 & $\begin{array}{c}-2,9 * \\
(-3,9 ;-2,0)\end{array}$ & $\downarrow$ & 3,1 & $\begin{array}{c}-2,9 * \\
(-3,9 ;-2,0)\end{array}$ & $\downarrow$ & 2,7 \\
\hline
\end{tabular}

* $\mathrm{p}<0,001$;

** $\mathrm{p}<0,01$;

$* * * p<0,05$ 
Em motociclistas do sexo masculino, as taxas aumentaram continuamente em todas as faixas etárias até 2012. O crescimento foi mais acentuado na faixa de 40 a 59 anos (15,5\% ao ano, IC: 14,0; $16,9)$ do que nas demais $(11,1 \%$ ao ano, IC: 10,$3 ; 11,9)$. Em 2012, a tendência se inverteu para queda, o decréscimo foi maior na faixa de 20 a 39 anos $(15,8 \%$ ao ano, IC: 12,$7 ; 18,7)$ do que nas demais $(8,5 \%$ ao ano, IC: 5,9; 11,0). A partir de 2015, o crescimento cessou nas faixas de 15 a 19 e de 60 anos e mais e, nas de 20 a 59 anos, as taxas voltaram a aumentar (7,2\% ao ano, IC: 4,0; 10,4). Em 2019, as taxas estimadas nas faixas de 15 a 19 e de 20 a 39 atingiram patamares bastante elevados: 144,8 e 164,4 por 100 mil habitantes, respectivamente. Durante todo o período, as taxas foram maiores nestas faixas do que nas demais.

A taxa de acidentes com homens ocupando um veículo permaneceu estável na faixa etária de 15 a 19 anos até 2015 , quando passou a cair $(11,8 \%$ ao ano, IC: 4,9; 18,4$)$ até o final do período. Nas demais faixas, as taxas cresceram até 2007 (4,3\% ao ano, IC: 2,7; 5,8), quando as tendências se inverteram e as taxas passaram a cair de 4,9\% (IC: 3,$9 ; 5,9)$ a 7,6\% (IC: 6,$4 ; 8,7$ ) ao ano até o final do período. A faixa de 20 a 39 anos foi responsável pelas maiores taxas durante todo o período.

A tendência da taxa de atropelamentos no sexo feminino entre 2000 e 2007 foi de crescimento, mais intenso nas faixas de 0 a 19 e de 40 a 59 anos (5,2\% ao ano, IC: 4,3; 6,2) do que nas demais $(2,4 \%$ ao ano, IC: 1,5; 3,3). Entre 2007 e 2012 , o quadro permaneceu inalterado em todas as faixas etárias, exceto na de 0 a 14 anos, em que a tendência se inverteu para queda $(6,2 \%$ ao ano, IC: 5,7; 7,4) e permaneceu assim até o final do período de estudo. Nas faixas acima de 14 anos, a tendência inverteu-se somente em 2012, quando as taxas passaram a cair (15,9\% ao ano, IC: 13,2; 18,5), mas a queda cessou em 2015. Durante todo o período, as taxas foram maiores na faixa de 60 anos e mais do que nas demais. Em 2019, a taxa ajustada nesta faixa foi de 18,8 por 100 mil habitantes.

Entre ciclistas mulheres, as taxas cresceram acentuadamente entre 2000 e 2007 em todas as faixas etárias $(14,5 \%$ ao ano, IC: 10,$7 ; 18,4)$. Em 2007, as taxas passaram a cair na faixa de 0 a 14 anos $(8,6 \%$ ao ano, IC: 6,$5 ; 10,6)$ e tornaram-se estáveis na faixa de 60 anos e mais; este quadro permaneceu até o final do período de estudo. As taxas também caíram na faixa de 15 a 19 anos (16,7\% ao ano, IC: 9,8; $23,1)$ até 2012 e nas faixas de 20 a 39 anos $(8,6 \%$ ao ano, IC: 6,5; 10,6) até 2015 . Na faixa de 40 a 59 anos, houve estabilidade até 2012. Em 2012, as taxas voltaram a crescer nas faixas de 15 a 19 e de 40 a $59 \operatorname{anos}(5,9 \%$ ao ano, IC: 0,3; 11,7). Em 2015, a taxa também voltou a crescer na faixa de 20 a 39 anos, mas de modo mais acentuado $(25,3 \%$ ao ano, IC: 13,$7 ; 37,6)$. As taxas foram maiores nas faixas abaixo de 20 anos do que nas demais na maior parte do período de estudo.

Para acidentes com motocicleta no sexo feminino, a tendência foi de crescimento acentuado em todas as faixas etárias até 2007 (15,7\% ao ano, IC: 13,8; 17,6). Entre 2007 e 2012, o quadro não mudou na faixa de 40 a 59 anos, mas nas demais o crescimento tornou-se menos acentuado (5,1\% ao ano, IC: 2,9; 7,3). Em 2012, a tendência inverteu-se para queda em todas as faixas etárias. Particularmente, em mulheres de 0 a 14 anos e de 60 anos e mais, as taxas caíram 14,2\% ao ano (IC: 10,8; 17,5) até o final do período de estudo. Para aquelas de 15 a 59 anos houve queda de 8,7\% ao ano (IC: 4,9; 12,2) até 2015 , mas a partir daí as taxas voltaram a crescer nas faixas de 15 a 39 anos (4,9\% ao ano, IC: 0,7; 9,3) e o decréscimo cessou na faixa de 40 a 59 anos. Durante todo o período as taxas foram maiores na faixa de 15 a 19 anos, seguida da de 20 a 39 anos. Em 2019, as taxas estimadas nestas faixas foram 23,4 e 13,8 por 100 mil habitantes, respectivamente.

A taxa de acidentes com mulheres ocupando um veículo cresceu entre 2000 e 2007, mais acentuadamente nas faixas de 0 a 19 anos (5,5\% ao ano, IC: 2,$2 ; 9,0)$ do que nas demais (2,4\% ao ano, IC: 0,3; 4,5). Em 2007, as tendências se inverteram para queda. Nas faixas acima de 14 anos as taxas caíram $2,9 \%$ ao ano (IC: 2,$0 ; 3,9$ ) até o final do período de estudo. Na faixa de 0 a 14 anos, a taxa caiu 10,8\% ao ano (IC: 5,2; 16,3) até 2012, quando a queda cessou.

De um modo geral, a análise de resíduos mostrou que o modelo estava bem ajustado, com poucos outliers, exceto para os acidentes com ciclistas na faixa etária de 60 anos e mais, e ocupantes de veículos na faixa etária de 0 a 14 anos. Nesses subgrupos em particular, a variabilidade das taxas ao longo do tempo foi muito superior à dos demais, dificultando a obtenção de um bom ajuste. 


\section{Discussão}

Houve uma predominância de vítimas do sexo masculino (80,5\%), com idade entre 20 e 49 anos $(71,2 \%)$, motociclistas ou pedestres $(76,5 \%)$, perfil observado anteriormente em outros estudos no Brasil 5,8,13 e no mundo 2,3.

De um modo geral, o período de 2000 a 2007 foi marcado pelo crescimento intenso das taxas de hospitalização por acidentes de trânsito no Município de São Paulo, para todos os meios de transporte, em ambos os sexos e na maioria das faixas etárias. $\mathrm{O}$ momento em que as taxas pararam de crescer ou que eventualmente passaram a cair foi diferente para os diversos meios de transporte. Para ocupantes de veículos e ciclistas, a tendência na maioria das faixas etárias inverteu-se para uma de queda em 2008, mas para pedestres e motociclistas isto só ocorreu em 2012.

Na tentativa de diminuir os acidentes de trânsito, várias medidas de segurança no trânsito foram implementadas ao longo dos anos, entre elas, a Lei Seca (Lei no 11.705, de 2008), estabelecendo limite de tolerância zero de alcoolemia para condutores de veículos e a Nova Lei Seca (Lei no 12.760, de 2012), mais rígida do que a lei anterior e com mais esforços na fiscalização. A relação entre acidentes de trânsito e consumo de álcool tem sido bem documentada na literatura nacional e internacional, e é uma das principais causas de morbimortalidade, atingindo, sobretudo, homens jovens 5,14,15.

Alguns estudos avaliaram o impacto da primeira Lei Seca 16,17,18,19,20,21,22 e, embora tenham concluído que houve um impacto positivo, foram baseados na comparação de curtos períodos de tempo antes e depois da sua implementação, de modo que as tendências não foram consideradas. Em tempos de observação tão curtos, as mudanças poderiam ser explicadas por meras oscilações nas séries históricas 23. De fato, Moura et al. 17 relatam que nos dois primeiros meses após a sua implantação, a frequência dos condutores que informaram dirigir após beber diminuiu de 2,2\% para 1,3\%, mas voltou a aumentar para 2,8\%, em 2009. Outros estudos que buscaram avaliar o impacto das leis por meio de séries históricas mais longas tiveram como foco principal a Lei Seca e observaram alguns efeitos positivos nas capitais brasileiras e no Distrito Federal 24, no Paraná 25, Rio de Janeiro 23 e Alagoas 26.

De acordo com os resultados desse estudo, que avaliou a tendência por longos períodos antes e depois das duas leis, pode-se dizer que houve um efeito positivo da primeira lei para ocupantes de veículos e ciclistas e, da segunda, para os quatro meios de transporte considerados, mas em especial para pedestres e motociclistas, cujas taxas apresentaram as maiores quedas percentuais, de modo que a segunda lei teve um impacto maior do que a primeira. Essas leis não foram medidas isoladas e outros fatores devem ser considerados para explicar a queda observada nas taxas, entre eles, a fiscalização. A sua eficiência foi apontada em alguns estudos, juntamente com a ressalva de que o afrouxamento na fiscalização pode ter levado a um retrocesso dos progressos alcançados 5,16,18,23,24,25,27.

A redução dos limites de velocidade, implementada em 2015, também deve ser considerada. Segundo a Organização Mundial da Saúde (OMS), a velocidade é um dos fatores mais importantes na determinação de um acidente de trânsito e a gravidade da lesão é particularmente crítica para os usuários mais vulneráveis, como pedestres, ciclistas e motociclistas, bem como para crianças e idosos 28 . Embora esta medida tenha trazido benefícios para a redução do número de acidentes, mortos e feridos no trânsito, segundo a Companhia de Engenharia de Tráfego (CET) 29, os limites de velocidade voltaram a aumentar em algumas vias em 2017.

Além dessas medidas, a Resolução no 27.731, do Conselho Nacional de Trânsito (CONTRAN), de 2008 (que determina o transporte de crianças menores nos bancos traseiros com equipamentos de retenção adequados, como a cadeirinha) e a realização de campanhas para o uso do cinto de segurança, contribuem para explicar a queda das taxas em ocupantes de veículos observada a partir de 2008. Aliados à Nova Lei Seca e à redução dos limites de velocidade, as Resoluções no 311 e no 312 do CONTRAN 30, ambas de 2009 (que determinam a obrigatoriedade dos sistemas de airbag e ABS como itens de série dos veículos a partir de 2010) contribuíram para que as taxas continuassem em queda até o final do período. Entretanto, vale ressaltar que os homens jovens de 20 a 39 anos são aqueles que apresentaram as maiores taxas de internação nessa categoria. Esta faixa etária, em conjunto com a de 15 a 19 anos, certamente merece especial atenção em medidas de planejamento de trânsito.

As taxas para acidentes com ciclistas caíram entre 2008 e 2012 em todos os subgrupos, resultado compatível com o do estudo de mortalidade de ciclistas na Região Sudeste entre 2000 e 201031. Entre 2012 e 2015 continuaram caindo, principalmente no sexo masculino. Além dos fatores citados 
anteriormente, outros influenciaram no comportamento das taxas nesse meio de transporte. Segundo a CET 32, antes de 2007 existiam apenas 5,8km de ciclovias. Em 2012, a malha constituída de ciclovias, ciclofaixas e ciclorrotas totalizava 84,1 km. Entre 2015 e 2019, este número passou de 380 para $516 \mathrm{~km}$, mas ainda assim as taxas de internação de ciclistas voltaram a aumentar entre os indivíduos de 15 a 59 anos, que constituem a faixa etária economicamente ativa. A ida e volta ao trabalho é o principal motivo de locomoção por meio de bicicleta (68\%) 33. Com o aumento da malha, a frota, o número de usuários e de viagens, o volume de tráfego de bicicletas também aumentou 32,33. Além disso, o capacete e outros equipamentos de segurança não são obrigatórios para ciclistas segundo a legislação brasileira ${ }^{30}$, ainda que estudos demostrem sua efetividade na redução de traumas e lesões 34,35. É razoável conjecturar que os acidentes acontecem preferencialmente nos trechos não cobertos pela malha.

A tendência das taxas de atropelamento de crianças entre 0 a 14 anos de ambos os sexos passou a ser de queda a partir de 2008, mas nas demais faixas etárias isto só aconteceu a partir de 2012. Estudos de mortalidade já haviam reportado queda nas taxas para pedestres no Brasil entre 1996 e 2015 e no mundo entre 2007 e 2010 36. Neste estudo, o decréscimo observado cessou em homens acima de 20 anos e em mulheres acima de 15 anos a partir de 2015, o que pode ser um alerta para os anos futuros. A população de idosos requer especial atenção, por serem as principais vítimas de atropelamento.

As taxas para motociclistas cresceram até 2012, mais acentuadamente no sexo masculino (de $11 \%$ a 16\% ao ano). Embora tenha havido um decréscimo pontual nas taxas de 2007 para 2008, sugerindo um possível impacto da Lei Seca, um perfil de queda não se configurou nos anos seguintes. A partir de 2012, as taxas caíram em ambos os sexos, em todas as faixas etárias, mais acentuadamente entre homens de 15 a 39 anos (15,8\% ao ano), responsáveis pelas maiores taxas observadas em homens até então. Além da Nova Lei Seca e da redução dos limites de velocidade, outras medidas ajudam a explicar esse decréscimo, como restrição à circulação de motos na Marginal Tietê, em 2010, e a criação de faixas de parada exclusiva para motos à frente dos demais veículos nos semáforos, em 2013. Esta norma permite que as motos se distanciem dos carros nos primeiros momentos após a abertura do semáforo, evitando ultrapassagens e o risco inerente à esta manobra. Os resultados desse estudo indicam que, apesar dessas medidas, a tendência nas faixas etárias de 15 a 39 anos tem sido de aumentos nos últimos cinco anos, principalmente no sexo masculino. Em 2019, as taxas ajustadas para homens nessas faixas superaram 140 por 100 mil habitantes. O cenário chama a atenção para este grupo em especial, responsável por 81.264 internações, mais de 42\% das internações por acidentes de trânsito no período.

Houve um aumento expressivo no número de motocicletas em São Paulo nos últimos vinte anos. Enquanto a frota automotiva da cidade dobrou de 2001 para 2019, passando de cerca de 4 milhões de veículos para cerca de 8,6 milhões, a frota de motocicletas mais do que quadruplicou, passando de cerca de 269 mil para 1,2 milhões 10 .

Em uma cidade com sérios problemas de mobilidade como São Paulo, onde o trânsito não flui, a motocicleta acabou sendo uma alternativa do cidadão para ganhar fluidez no trânsito, uma vez que ocupam menos espaço e podem transitar no "corredor", entre as faixas de carros, ganhando maior velocidade. A agilidade no deslocamento, mesmo em vias congestionadas ou horários de pico, tornou esse meio de transporte extremamente atraente, inclusive do ponto de vista comercial.

Os motoboys, entregadores profissionais que utilizam a motocicleta como meio de transporte e de sustento, surgiram na década de 1980, tiveram sua profissão regulamentada em 2009 (Lei no 12.009) e tornaram-se fundamentais para a logística de empresas nos mais diversos setores. Atualmente já são cerca de 200 mil (Sindicato dos Motociclistas de São Paulo. http://www.sindimotosp.com.br/, acessado em 10/Dez/2019). Em um cenário de imensas desigualdades sociais e desemprego, essa atividade possibilita o sustento de uma grande parcela de jovens sem qualificação profissional. Entretanto, realizam tarefas remuneradas de acordo com sua produtividade, sofrem pressão de clientes e de patrões para serem ágeis, o que exacerbaria a busca pela rapidez em manobras arriscadas, em detrimento do respeito à legislação do trânsito e da prática de direção defensiva 37 . Aliado a isto, algumas características de jovens do sexo masculino, como audácia, imaturidade, sensação de invulnerabilidade, tendência de superestimar capacidades e inexperiência na condução, somadas à necessidade de integrar-se ao grupo, que os estimulam a ultrapassar limites e a transgredir, favorecem a ocorrência de acidentes 5,38, além de colocar em risco os usuários dos demais veículos e os pedestres. 
Adicionalmente, a dificuldade de visualização de motocicletas pelos demais motoristas, a maior exposição do corpo e a negligência no uso de equipamentos de proteção colocam esses usuários em uma categoria especialmente suscetível. As lesões decorrentes sofridas por motociclistas costumam ser mais graves, frequentemente na cabeça e em membros superiores e inferiores, resultando em longos períodos de hospitalização e sequelas graves, por vezes, fatais 39 . Esta dinâmica reflete uma interessante contradição: a mesma sociedade que utiliza (e aprecia) os serviços de profissionais, exigindo deles a maior rapidez possível, torna e trata esses motociclistas como elementos perigosos no trânsito 37 .

Obviamente, este período de tempo ainda é curto para configurar com segurança um novo perfil de crescimento para os acidentes com motocicleta ou fazer previsões para os próximos anos, mas é suficiente para chamar a atenção para um problema que pode atingir níveis alarmantes em um futuro próximo.

Este estudo tem as limitações inerentes relacionadas ao uso de dados secundários, além de avaliar apenas uma parcela da população - os usuários do SUS. Entretanto, essa parcela não é desprezível, uma vez que 75,6\% dos brasileiros não têm plano de saúde privado e dependem do SUS na atenção à saúde 40 . Atualmente, aproximadamente $70 \%$ dos leitos de internação existentes no país são disponibilizados pelo SUS 41 .

Os acidentes de trânsito têm se mostrado consistentemente um problema de saúde pública na cidade de São Paulo e é possível que os benefícios de algumas medidas de segurança implementadas até agora tenham atingido seu limite. Uma reformulação das medidas de prevenção e controle e maiores esforços na fiscalização das leis de trânsito são necessárias, bem como a implementação de um sistema de transporte público eficiente que diminua a necessidade do transporte individual e, consequentemente, o excesso de veículos nas ruas.

\section{Colaboradores}

G. M. S. Conceição participou da concepção do estudo, análise e interpretação dos resultados obtidos, elaboração do texto e aprovação da versão final. G. P. Alencar e M. R. D. O. Latorre deram contribuições substanciais para a concepção do estudo, análise e interpretação dos resultados obtidos e revisão do texto.

\section{Informações adicionais}

ORCID: Gleice Margarete de Souza Conceição (0000-0002-5930-9024); Gizelton Pereira Alencar (0000-0002-2354-9050); Maria do Rosário Dias de Oliveira Latorre (0000-0002-5189-3457).

\section{Referências}

1. Lozano R, Naghavi M, Foreman K, Lim S, Shibuya K, Aboyans V, et al. Global and regional mortality from 235 causes of death for 20 age groups in 1990 and 2010: a systematic analysis for the Global Burden of Disease Study 2010. Lancet 2012; 380:2095-128.

2. World Health Organization. Global status report on road safety 2013: supporting a decade of action. Geneva: World Health Organization; 2013.

3. World Health Organization. Global status report on road safety 2018. Geneva: World Health Organization; 2018.

4. World Health Organization. Global health estimates: leading causes of DALYs. https:// www.who.int/data/gho/data/themes/mortali ty-and-global-health-estimates/global-healthestimates-leading-causes-of-dalys (acessado em 04/Jan/2021). 
5. Bacchieri G, Barros AJD. Acidentes de trânsito no Brasil de 1998 a 2010: muitas mudanças e poucos resultados. Rev Saúde Pública 2011; 45:949-63.

6. Lentsck MH, Sato APS, Aidar TMF. Panorama epidemiológico de dezoito anos de internações por trauma em UTI no Brasil. Rev Saúde Pública 2019; 53:83.

7. Andrade SSCA, Jorge MHPM. Estimativa de sequelas físicas em vítimas de acidentes de transporte terrestre internadas em hospitais do Sistema Único de Saúde. Rev Bras Epidemiol 2016; 19:100-11.

8. Marín-León L, Belon AP, Barros MBA, Almeida SDM, Restitutti MC. Tendência dos acidentes de trânsito em Campinas, São Paulo, Brasil: importância crescente dos motociclistas. Cad Saúde Pública 2012; 28:39-51.

9. Instituto Brasileiro de Geografia e Estatística. São Paulo - Panorama. https://cidades.ibge. gov.br/brasil/sp/sao-paulo/panorama (acessado em 12/Mar/2020).

10. Departamento Nacional de Trânsito. Frota de veículos. https://infraestrutura.gov.br/ component/content/article/115-portal-dena tran/8559-frota-de-veiculos-2019.html (acessado em 12/Mar/2020).

11. Draper NR, Smith H. Applied regression analysis. 3rd Ed. New York: John Wiley \& Sons; 1998.

12. Fox J. Applied regression analysis and generalized linear models. 3rd Ed. Thousand Oaks: Sage Publications; 2016.

13. Gawryszewski VP, Coelho HMM, Scarpelini S, Zan R, Jorge MHPM, Rodrigues EMS. Land transport injuries among emergency department visits in the state of São Paulo, in 2005. Rev Saúde Pública 2009; 43:275-82.

14. Abreu AMM, Lima JMB, Matos LN, Pillon SC. Uso de álcool em vítimas de acidentes de trânsito: estudo do nível de alcoolemia. Rev Latinoam Enferm 2010; 18(spe):513-20.

15. Damacena GN, Malta DC, Boccolini CS, Souza Júnior PRB, Almeida WS, Ribeiro LS. Consumo abusivo de álcool e envolvimento em acidentes de trânsito na população brasileira, 2013. Ciênc Saúde Colet 2016; 21:3777-86.

16. Nunes MN, Nascimento LFC. Análise espacial de óbitos por acidentes de trânsito, antes e após a Lei Seca, nas microrregiões do estado de São Paulo. Rev Assoc Méd Bras 2012; 58:685-90.

17. Moura EC, Malta DC, Morais Neto OL, Penna GO, Temporão JG. Direção de veículos motorizados após consumo abusivo de bebidas alcoólicas, Brasil, 2006 a 2009. Rev Saúde Pública 2009; 43:891-4.

18. Salgado RDS. O impacto da "Lei Seca" sobre o beber e dirigir em Belo Horizonte/MG. Ciênc Saúde Colet 2012; 17:971-6.

19. Malta DC, Soares Filho AM, Montenegro MMS, Mascarenhas MDM, Silva MMA, Lima $\mathrm{CM}$, et al. Análise da mortalidade por acidentes de transporte terrestre antes e após a Lei Seca - Brasil, 2007-2009. Epidemiol Serv Saúde 2010; 19:317-28.
20. Abreu AMM, Jomar RT, Thomaz RGF, Guimarães RM, Lima JMB, Figueiro RFS. Impacto da Lei Seca na mortalidade por acidentes de trânsito. Rev Enferm UERJ 2012; 20:21-6.

21. Mello-Jorge MHP, Koizumi MS. Acidentes de trânsito causando vítimas: possível reflexo da lei seca nas internações hospitalares. Revista Abramet 2009; 27:16-25.

22. Klabunde FC, Ghizzo Filho J, Freitas PF, Nazário NO. Impacto da Lei Seca na taxa de mortalidade ou acidentes de trânsito, Santa Catarina, entre 2005 e 2011. ACM Arq Catarin Med 2011; 46:108-17.

23. Jomar RT, Ramos DO, Fonseca VAOF, Junger WL. Effect of the zero-tolerance drinking and driving law on mortality due to road traffic accidents according to the type of victim, sex, and age in Rio de Janeiro, Brazil: an interrupted time series study. Traffic Inj Prev 2019; 20:227-32.

24. Malta DC, Berna RTI, Silva MMA, Claro RM, Silva Júnior JB, Reis AAC. Consumo de bebidas alcoólicas e direção de veículos, balanço da Lei Seca, Brasil 2007 a 2013. Rev Saúde Pública 2014; 48:692-6.

25. Abreu DROM, Souza EM, Mathias TAF. Impacto do Código de Trânsito Brasileiro e da Lei Seca na mortalidade por acidentes de trânsito. Cad Saúde Pública 2018; 34:e00122117.

26. Souza CDF, Paiva JPS, Leal TC, Silva LF, Machado MF, Araújo MDP. Mortality in motorcycle accidents in Alagoas (2001-2015): temporal and spatial modeling before and after the "Lei Seca". Rev Assoc Méd Bras 2019; 65:1482-8

27. Martins RHG, Ribeiro CBH, Fracalossi T, Dias NH. A Lei Seca cumpriu sua meta em reduzir acidentes relacionados à ingestão excessiva de álcool? Rev Col Bras Cir 2013; 40:438-42.

28. World Health Organization. Managing speed. Geneva: World Health Organization; 2017.

29. Companhia de Engenharia de Tráfego. Benefícios imediatos da redução das velocidades máximas permitidas: o caso das Marginais Tietê e Pinheiros. São Paulo: Companhia de Engenharia de Tráfego; 2016.

30. Conselho Nacional de Trânsito. Resoluções - CONTRAN. https://www.gov.br/infraes trutura/pt-br/assuntos/transito/conteudo-de natran/resolucoes-contran (acessado em 04/ Jan/2021).

31. Garcia LP, Freitas LRS, Duarte EC. Mortalidade de ciclistas no Brasil: características e tendências no período 2000-2010. Rev Bras Epidemiol 2013; 16:918-29.

32. Companhia de Engenharia de Tráfego. Plano cicloviário do município de São Paulo. São Paulo: Companhia de Engenharia de Tráfego; 2020.

33. Secretaria Estadual dos Transportes Metropolitanos; Companhia do Metropolitano de São Paulo. Pesquisa origem destino 2017 - a mobilidade urbana da região metropolitana de São Paulo. São Paulo: Secretaria Estadual dos Transportes Metropolitanos/Companhia do Metropolitano de São Paulo; 2017. 
34. Thompson DC, Rivara FP, Thompson R. Helmets for preventing head and facial injuries in bicyclists. Cochrane Database Syst Rev 2000; (2):CD001855

35. Fernandes CM, Boing AC. Mortalidade de pedestres em acidentes de trânsito no Brasil: análise de tendência temporal, 1996-2015. Epidemiol Serv Saúde 2019; 28:e2018079.

36. Rivara FP, Thompson DC, Thompson RS. Epidemiology of bicycle injuries and risk factors for serious injury. Inj Prev 2015; 21:47-51.

37. Montenegro MMS, Duarte EC, Prado RR, Nascimento AF. Mortalidade de motociclistas em acidentes de transporte no Distrito Federal, 1996 a 2007. Rev Saúde Pública 2011; 45:529-38.

38. American Academy of Pediatrics Committee on Injury and Poison Prevention and Committee on Adolescence. The teenage driver. Pediatrics 1996; 98:987-90.
39. Anjos KC, Rezende MR, Mattar R. Social and hospital costs of patients admitted to a university hospital in Brazil due to motorcycle crashes. Traffic Inj Prev 2017; 18:585-92.

40. Agência Nacional de Saúde Suplementar. Dados gerais. https://www.ans.gov.br/per fil-do-setor/dados-gerais (acessado em 10/ Mar/2020).

41. Departamento de Informática do Sistema Único de Saúde. CNES - Recursos Físicos - Hospitalar - Leitos de internação - Brasil. http:// tabnet.datasus.gov.br/cgi/deftohtm.exe?cnes/ cnv/leiintbr.def (acessado em 12/Mar/2020). 
Abstract

This study assessed the hospitalization rates from motor vehicle accidents in the Brazilian Unified National Health System (SUS) in residents of the city of São Paulo, Brazil, from 2000 to 2019, according to sex, age bracket, and means of transportation (pedestrians, cyclists, motorcyclists, and motor vehicle occupants). A segmented regression model with negative binomial response was adjusted with inflection points to accommodate possible changes in trends. 189,765 hospitalizations were recorded during the study period, mostly males (80.5\%) and from 20 to 49 years of age (71.2\%). The most frequent type of accident involved motorcyclists (42.8\%), followed by run-over pedestrians (33.7\%). In general, the period from 2000 to 2007 was marked by increasing hospitalization rates from motor vehicle accidents involving all means of transportation, in both sexes, and in most age brackets. The year when the rates stopped increasing (or in some cases began to drop) differed according to the means of transportation. For vehicle occupants and cyclists, the trend in most age brackets turned downward in 2008, but the same did not happen with pedestrians and motorcyclists until 2012. Starting in 2015, the decline stopped in pedestrians, and the rates in cyclists turned upward again in most age brackets. For motorcyclists, the rates turned upward again in men 20 to 59 years of age (7.2\% per year, exceeding 140 per 100,000 inhabitants in 2019) and in women 15 to 39 years of age (4.9\% per year). The benefits of traffic safety measures implemented thus far in Brazil may have reached their limit, so that the current control and prevention measures need to be revised.

Traffic Accidents; Transportation; Hospitalization; Morbidity

\section{Resumo}

Este estudio evaluó la tendencia de las tasas de internamiento por accidentes de tránsito en el Sistema Único de Salud, de residentes en el Municipio de São Paulo, Brasil, entre 2000 y 2019, según sexo, franja de edad y medio de transporte (peatones, ciclistas, motociclistas y ocupantes de vehiculo). Fue ajustado a un modelo de regresión segmentada con respuesta binomial negativa, con puntos de inflexión para acomodar posibles cambios de tendencia. Se registraron 189.765 internamientos $d u$ rante el periodo de estudio, la mayoría de hombres (80,5\%) con edad entre 20 y 49 años (71,2\%). El tipo de accidente más frecuente fue con motocicleta $(42,8 \%)$, seguido de atropellamientos de peatones (33,7\%). De modo general, el período de 2000 a 2007 estuvo marcado por el crecimiento de las tasas de hospitalización por accidentes de tránsito para todos los medios de transporte, en ambos sexos, y en la mayoría de las franjas de edad. El momento en el que las tasas pararon de crecer, o que eventualmente pasaron a caer, fue diferente para los diferentes medios de transporte. En el caso de ocupantes de vehículos y ciclistas, la tendencia en la mayoría de las franjas de edad se invirtió hacia una caída en 2008, pero en peatones y motociclistas, esto solo ocurrió en 2012. A partir de 2015, la caída cesó en peatones y las tasas en ciclistas volvieron a subir, en la mayoría de las franjas de edad. Para los motociclistas, las tasas volvieron a crecer en hombres de 20 a 59 años (7,2\% al año, alcanzando valores superiores a 140 por $100 \mathrm{mil}$ habitantes en 2019) y en mujeres, de 15 a 39 años (4,9\% al año). Es posible que los beneficios de las medidas de seguridad implementadas hasta ahora hayan alcanzado su limite, de modo que las actuales medidas de control y prevención deben ser revisadas.

Accidentes de Tránsito; Transportes;

Hospitalización; Morbilidad
Recebido em 07/Ago/2020

Versão final reapresentada em 15/Abr/2021

Aprovado em 26/Abr/2021 